\title{
Wound management with vacuum-assisted closure in postoperative infections after surgery for spinal stenosis
}

This article was published in the following Dove Press journal:

International Medical Case Reports Journal

22 December 2014

Number of times this article has been viewed

\author{
Fatih Karaaslan' \\ Șevki Erdem² \\ Musa Uğur Mermerkaya' \\ 'Department of Orthopaedics and \\ Traumatology, Bozok University \\ Medical School, Yozgat, Turkey; \\ ${ }^{2}$ Department of Orthopaedics and \\ Traumatology, Haydarpașa Numune \\ Training Hospital, Istanbul, Turkey
}

Correspondence: Fatih Karaaslan Department of Orthopaedics and Traumatology, Faculty of Medicine, Bozok University, 18 Madrasa Adnan Menderes, Boulevard, Yozgat 66200, Turkey

Tel +903542I2 7060

Email fkaraaslan@gmail.com
Objective: To evaluate the results of negative-pressure wound therapy (NPWT) in the treatment of surgical spinal site infections.

Materials and methods: The use of NPWT in postoperative infections after dorsal spinal surgery (transforaminal lumbar interbody fusion plus posterior instrumentation) was studied retrospectively. From February 2011 to January 2012, six patients (females) out of 317 ( 209 females; 108 males) were readmitted to our clinic with surgical site infections on postoperative day 14 (range 9-19) and were treated with debridement, NPWT, and antibiotics. We evaluated the clinical and laboratory data, including the ability to retain the spinal hardware and recurrent infections.

Results: The incidence of deep postoperative surgical site infection was six (1.89\%) patients (females) out of 317 patients (209 females; 108 males) at 1 year. All patients completed their wound NPWT regimen successfully. An average of 5.1 (range 3-8) irrigation and debridement sessions was performed before definitive wound closure. The mean follow-up period was 13 (range 12-16) months. No patient had a persistent infection requiring partial or total hardware removal. The hospital stay infection parameters normalized within an average of 4.6 weeks.

Conclusion: The study illustrates the usefulness of NPWT as an effective adjuvant treatment option for managing complicated deep spinal surgical wound infections.

Keywords: surgical infection, NPWT, VAC, TLIF

\section{Introduction}

Postoperative wound infection after spinal surgery is a serious though uncommon problem, which still occurs despite the use of prophylactic antibiotics and advances in surgical techniques and postoperative care. ${ }^{1}$ Infection of the spine after instrumentation is a challenge for the spinal surgeon. The cumulative incidence of postoperative spinal wound infections was found to be $0.6 \%$ for minimally invasive transforaminal lumbar interbody fusion (TLIF) and $4.0 \%$ for "open" TLIF. ${ }^{2}$ According to a National Nosocomial Infection Surveillance report, several factors increase the rate of postoperative infections in common procedures, such as spinal fusions and laminectomies. ${ }^{3}$ Instrumentation increases the rate of infection, as do malnutrition, an extended preoperative hospital stay, and increased blood loss. ${ }^{4}$

Various treatment protocols for debridement, soft-tissue management, and antibiotic therapy have been recommended, but these have had mixed results. The use of Vacuum-Assisted Closure ${ }^{\circledR}$ (VAC ${ }^{\circledR}$; Kinetic Concepts, San Antonio, TX, USA), a type of negative-pressure wound therapy (NPWT), in wound therapy has gained popularity for the management of acute, subacute, and chronic wounds. By exposing the wound 
bed to controlled negative pressure, wound therapy removes edema fluid, increases blood flow, decreases the bacterial load, and stimulates the proliferation of reparative granulation tissue. The NPWT system also assists the debridement of necrotic tissue and acts as a sterile barrier. It has been used successfully to treat open wounds of the extremities, thoracic and abdominal walls, and pressure or diabetic ulcers. 5,6

This retrospective study reports six patients in whom NPWT was used as a new approach to treat deep subfascial infections after dorsal spinal surgery based on temporary soft tissue coverage with a reduction in the dead space and delayed primary wound closure, without removing the implants.

\section{Patients and methods}

From February 2011 to January 2012, TLIF and posterior instrumentation were performed in 317 patients ( 209 females; 108 males) at our clinic. Cancellous chip allografts were used to fuse the arthrodesis site. All instrumentation used was made of titanium (Teknomed Spinal instrumentation Systems, Izmir, Turkey). Six of 317 patients were admitted to our clinic approximately 2 weeks after spinal surgery, with early surgical site infections and exposed instrumentation. The infected wounds were in the lumbar region. The risk factors, comorbidities, previous spinal surgery, preoperative admission history, and medical records of the six patients were reviewed. The laboratory evaluation included infection markers, such as the erythrocyte sedimentation rate (ESR), C-reactive protein (CRP) level, and white blood cell (WBC) count. The infection sites of the six patients were also evaluated with magnetic resonance imaging (MRI) if there were any signs of osteomyelitis.

After completing the clinical, laboratory, and radiological evaluations, the six patients were treated with serial debridement and NPWT (Figure 1). The VAC ${ }^{\circledR}$ system was applied, and intraoperative cultures were obtained at the first debridement session. The intraoperative debridement involved thorough lavage and the removal of all macroscopic contamination, devitalized tissue, and allograft bone (Figure 2). After cultures were obtained, parenteral antibiotic treatment was administered for at least 4 weeks, and oral sulfamethoxazole and trimethoprim (800 $\mathrm{mg}$ and $160 \mathrm{mg}$, respectively) 1-2 times a day was continued for at least 1 month further after hospital discharge. The wounds were treated with a negative pressure of $100 \mathrm{mmHg}$, applied continuously. The $\mathrm{VAC}^{\circledR}$ dressings were changed at 3-day intervals until granulation tissue formed, under sedoanalgesia and sterile conditions in the operating room. When there was no drainage from the wound, we closed the wound in anatomical layers.
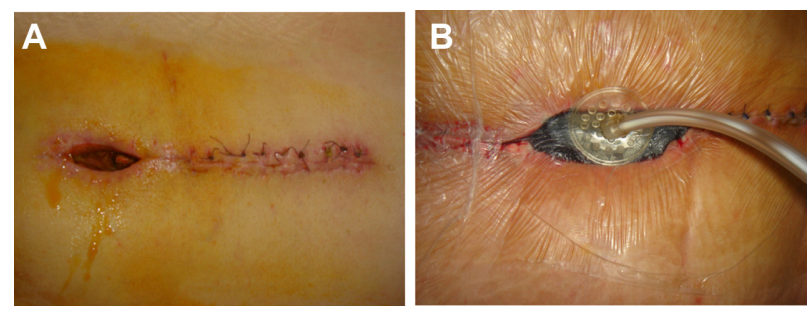

Figure I Pre-VAC spinal wound (A); after application of the VAC device (B). Abbreviation: VAC, vacuum-assisted closure.

All of the patients were evaluated for eradication of infection, using clinical, radiological, and laboratory indicators, such as the presence of spinal pseudarthrosis, ESR, CRP level, WBC count, wound culture negativity, and need for additional surgery after application of the $\mathrm{VAC}^{\circledR}$ system. All patients were evaluated for a minimum of 6 months after definitive closure of the subfascial wound infection.

\section{Results}

Of the TLIF patients, $65.9 \%$ were female, and all of the patients with surgical site infections were female. At our clinic, the incidence of surgical spinal infection after open TLIF and posterior instrumentation was $1.89 \%$. The mean age of the infected patients was 55.6 (range 49-62) years. Comorbidities included diabetes, chronic renal failure, alcohol abuse, obesity, malnutrition, rheumatoid arthritis, and smoking. All patients underwent the same procedure (TLIF plus posterior fusion with instrumentation) in the lumbar spinal region as the index operation (Table 1). A combination of superficial and deep drains was used in the primary procedure in all cases. The average surgery time was 2.1 (range 1.8-3) hours. The infection presented a mean of 14 days after surgery. Overall, an average of 5.1 (range 3-8) debridement and irrigation procedures was performed before

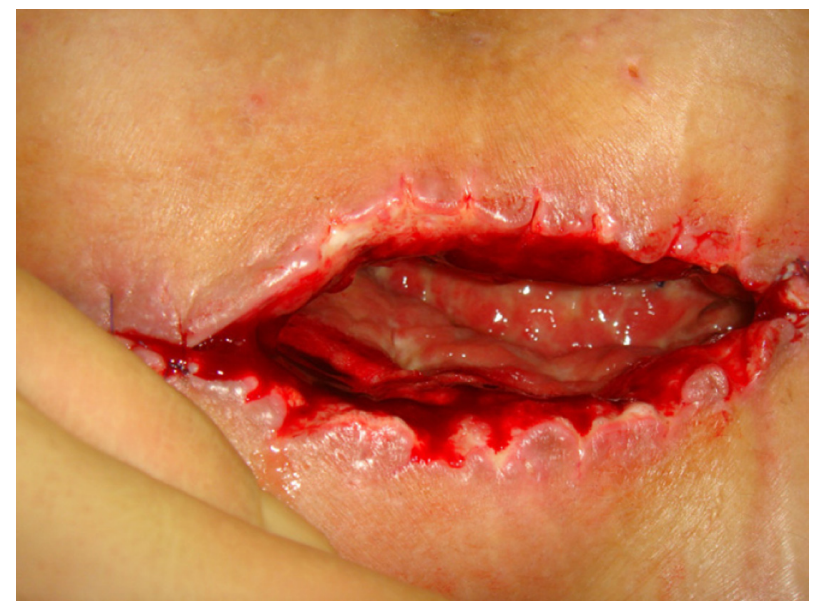

Figure 2 After surgical debridement and before VAC application. Abbreviation: VAC, vacuum-assisted closure. 


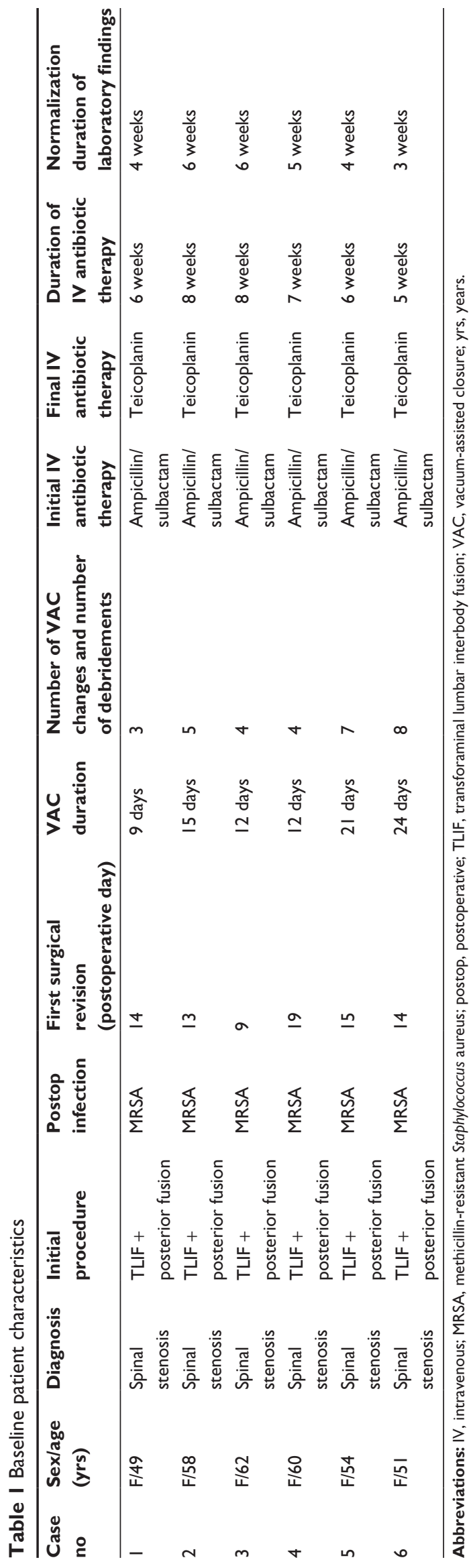

the definitive wound closure operation. The average time of previous spinal surgery to first revision surgery was 14 (range 9-19) days and VAC ${ }^{\circledR}$ duration of patients was 15.5 (range 9-24) days. The average follow-up of the infected patients was 13 (12-16) months.

All patients were started on parenteral ampicillin/ sulbactam $(1 \mathrm{~g})$, and received one to four doses as empirical broad-spectrum antibiotic therapy until culture results and antibiograms were available; then, the treatment was changed to a more specific antibiotic. Culture specimens from all patients were positive for methicillin-resistant Staphylococcus aureus (MRSA). Therefore, ampicillin/sulbactam therapy was stopped and parental teicoplanin therapy was started, at $400 \mathrm{mg}$ twice daily as the initial dosage and continued at $400 \mathrm{mg}$ once a day after the second day. The average duration of parenteral antibiotic therapy was 6.6 (range 5-8) weeks. Culture negativity and normalization of laboratory markers occurred at an average of 4.6 (range 3-6) weeks. All patients achieved clean closed wounds with retention of the instrumentation. At 2 months after the first debridement, follow-up MRI showed no signs of infection radiologically. The mean follow-up period was 13 (range 12-16) months.

\section{Discussion}

First of all, we evaluated this situation as hospital-acquired infections. So, we developed a multidisciplinary clinical approach, and our sterilization program and infection control protocols were reviewed.

We now believe that preoperative patients should be tested with nasal and rectal swabs, and if they are positive, they could be pretreated with oral preoperative antibiotics that would provide better MRSA coverage. This may lessen the chance of infection. Also, education is key to infection prevention. Experienced nurses, such as nurse practitioners, clinicians, or preceptors, should be diligent in teaching new nurses about hand hygiene, gloving, sterile techniques, and high-risk patients.

In our experience, NPWT is a useful tool in the complex management of deep infections in spinal wounds. Although we had some success treating patients with the NPWT device, the number of patients in this retrospective review was too small and the follow-up period too short to thoroughly evaluate the effectiveness of the NPWT system.

The reported rate of spinal infection increases with the complexity of the procedure, ranging between $0.6 \%$ and $4 \% .{ }^{2}$ The added benefit of the NPWT device over simple irrigation, debridement, and open-wound treatment is the effect of continuous negative pressure on wound healing (ie, fluid 
removal, increased circulation, and granulation tissue regeneration). ${ }^{7}$

In most studies, the NPWT dressing was placed after debridement and irrigation of the wound. ${ }^{8-10}$ Yuan-Innes et al reported the successful use of NPWT in two patients with infected and exposed spinal hardware. ${ }^{11}$ Mehbod et al ${ }^{12}$ described 20 cases in which NPWT was used in the management of deep wound infections occurring after spinal fusion procedures and reported clean closed wounds without hardware removal in all cases. ${ }^{12}$ In their series, approximately 2.2 (range 2-3) procedures were required until definitive closure, which occurred on average 7 (range 5-14) days after the initial placement. Our patients needed more debridement sessions and a much longer NPWT duration until wound closure than was reported by Mehbod et al. ${ }^{12}$ The difference might have resulted from our aggressive treatment strategy.

Lehner et $\mathrm{al}^{13}$ reported results of the treatment of infected orthopedic implants with NPWT, with instillation in 32 patients treated after a diagnosis of early or late implant infection. ${ }^{13}$ In that multicenter, prospective, nonrandomized study, $86.4 \%$ of the patients with acute implant infections and $80 \%$ with chronic infections were treated successfully. The mean duration of NPWT was 16.3 days. Our results are consistent with theirs, but our NPWT system did not have an instillation option.

Other articles reporting case series, and individual cases have addressed potential complications associated with NPWT use, although none of these articles has appeared in the spine literature. Clinicians generally mention the risk of pain due to the sponge volume and negative pressure, the growth of granulation tissue into the sponge, possible minor bleeding at dressing changes, odor, and skin erosion around the suction tube. ${ }^{14-16}$ No complications developed in our cases.

In our opinion, the key component of the successful treatment of infections after dorsal spine surgery is operative management with repeated second-look operations and copious debridement. We do not use a local irrigation system for infected wounds because we believe that these systems limit the irrigation to a small part of the wound. As a technique for reducing the dead space and conditioning the wound, the NPWT dressing has important merits: the temporary closure prevents contamination and desiccation of the wound and protects it from injury.

In summary, an NPWT system is an effective adjunct in closing postoperatively infected spinal wounds and reduces the need for hardware removal during treatment. Infections caused by multiple bacterial species or MRSA are more likely to need repeat debridement and NPWT.

\section{Disclosure}

The authors report no conflicts of interest in this work.

\section{References}

1. Weinstein MA, McCabe JP, Cammisa FP. Postoperative spinal wound infection: a review of 2,391 consecutive index procedures. $J$ Spinal Disord. 2000;13(5):422-426.

2. Parker SL, Adogwa O, Witham TF, Aaronson OS, Cheng J, McGirt MJ. Post-operative infection after minimally invasive versus open transforaminal lumbar interbody fusion (TLIF): literature review and cost analysis. Minim Invasive Neurosurg. 2011;54(1):33-37.

3. National Nosocomial Infections Surveillance System. National Nosocomial Infections Surveillance (NNIS) System Report, data summary from January 1992 through June 2004, issued October 2004. Am $J$ Infect Control. 2004;32(8):470-485.

4. Beiner JM, Grauer J, Kwon BK, Vaccaro AR. Postoperative wound infections of the spine. Neurosurg Focus. 2003;15(3):E14.

5. Scholl L, Chang E, Reitz B, Chang J. Sternal osteomyelitis: use of vacuumassisted closure device as an adjunct to definitive closure with sternectomy and muscle flap reconstruction. J Card Surg. 2004;19(5):453-461.

6. Cothren CC, Moore EE, Johnson JL, Moore JB, Burch JM. One hundred percent fascial approximation with sequential abdominal closure of the open abdomen. Am J Surg. 2006;192(2):238-242.

7. Ousey KJ, Atkinson RA, Williamson JB, Lui S. Negative pressure wound therapy (NPWT) for spinal wounds: a systematic review. Spine J. 2013;13(10):1393-1405.

8. Vicario C, de Juan J, Esclarin A, Alcobendas M. Treatment of deep wound infections after spinal fusion with a vacuum-assisted device in patients with spinal cord injury. Acta Orthop Belg. 2007;73(1):102-106.

9. Ploumis A, Mehbod AA, Dressel TD, Dykes DC, Transfeldt EE, Lonstein JE. Therapy of spinal wound infections using vacuum-assisted wound closure: risk factors leading to resistance to treatment. $J$ Spinal Disord Tech. 2008;21(5):320-323.

10. Vikatmaa P, Juutilainen V, Kuukasjärvi P, Malmivaara A. Negative pressure wound therapy: a systematic review on effectiveness and safety. Eur J Vasc Endovasc Surg. 2008;36(4):438-448.

11. Yuan-Innes MJ, Temple CL, Lacey MS. Vacuum-assisted wound closure: a new approach to spinal wounds with exposed hardware. Spine (Phila Pa 1976). 2001;26(3):E30-E33.

12. Mehbod AA, Ogilvie JW, Pinto MR, et al. Postoperative deep wound infections in adults after spinal fusion: management with vacuumassisted wound closure. J Spinal Disord Tech. 2005;18(1):14-17.

13. Lehner B, Fleischmann W, Becker R, Jukema GN. First experiences with negative pressure wound therapy and instillation in the treatment of infected orthopaedic implants: a clinical observational study. Int Orthop. 2011;35(9):1415-1420.

14. Argenta LC, Morykwas MJ. Vacuum-assisted closure: a new method for wound control and treatment: clinical experience. Ann Plast Surg. 1997;38(6):563-576; discussion 577.

15. DeFranzo AJ, Argenta LC, Marks MW, et al. The use of vacuum-assisted closure therapy for the treatment of lower-extremity wounds with exposed bone. Plast Reconstr Surg. 2001;108(5):1184-1191.

16. Masden D, Goldstein J, Endara M, Xu K, Steinberg J, Attinger C. Negative pressure wound therapy for at-risk surgical closures in patients with multiple comorbidities: a prospective randomized controlled study. Ann Surg. 2012;255(6):1043-1047. 
International Medical Case Reports Journal

Dovepress

\section{Publish your work in this journal}

The International Medical Case Reports Journal is an international, peer-reviewed open-access journal publishing original case reports from all medical specialties. Previously unpublished medical posters are also accepted relating to any area of clinical or preclinical science. Submissions should not normally exceed 2,000 words or

4 published pages including figures, diagrams and references. The manuscript management system is completely online and includes a very quick and fair peer-review system, which is all easy to use. Visit $\mathrm{http}: / / \mathrm{www}$.dovepress.com/testimonials.php to read real quotes from published authors.

Submit your manuscript here: http://www.dovepress.com/international-medical-case-reports-journal-journal 